\title{
Wave run-up and overtopping over smooth and rock slopes of coastal structures without crown walls
}

\author{
Janaka J. Wijetunge \\ Department of Civil Engineering, Faculty of Engineering, University of Peradeniya, Peradeniya.
}

\begin{abstract}
This paper is concerned with a comparatively large-scale laboratory investigation carried out to examine the overtopping performance of a straight, rock slope without a crown wall. Measurements made over a smooth slope to verify the reliability of the experimental set-up are also reported. The wave run-up and overtopping data from the present tests with regular waves, when appropriately scaled based on the assumption of Rayleigh distribution for wave heights, show good agreement with corresponding data from irregular waves. The average overtopping discharges over the smooth and rock slopes have also been compared with different models available in the literature. Moreover, the overtopping rates for the comparatively large-scale rock slope tested in the present study show good agreement with the previous measurements reported in Van der Meer when scaled with a roughness reduction factor of 0.55 . The overtopping measurements for the rock slope without a crown wall have also been compared with the overtopping model employed by Bradbury and Allsop for their measurements over rock slopes with crown walls.
\end{abstract}

Keywords: Coastal structures, rock slope, smooth slope, wave overtopping, wave run-up

\section{INTRODUCTION}

Wave action on a sloping coastal structure causes the water surface to oscillate over a vertical range which is generally larger than the incident wave height. The extreme upper levels reached by the waves travelling up the slope is termed the run-up. If extreme run-up level exceeds the top level or the crest of the slope, the waves will overtop the structure.

Such excessive run-up and consequent overtopping of a breakwater or pier can be detrimental to harbour operations such as small craft mooring and most types of commercial cargo handling. Moreover, overtopping of a rubble seawall or a revetment can cause severe erosion and damage to property behind the structure.
Such incidents of overtopping of breakwaters and revetments causing damage to property and eventually to the economy of the nation are frequent in Sri Lanka even during mild storms. This is partly owing to the fact that very little data are available for the coastal designers on the overtopping performance of the type of rubble-mound structures used in Sri Lanka, i.e., straight rubble-mound slopes without crown walls (This has also been pointed out by Van der Meer ${ }^{1}$ ). The overtopping formulae recommended in the Coastal Engineering Manual $^{2}$ (CEM) and in other literature are essentially empirical as they are based on hydraulic model tests for specific structure geometries. For example, CEM recommended formulae of Bradbury \& Allsop ${ }^{3}$, Aminti Franco $^{4}$, Pedersen \& Burcharth ${ }^{5}$ and Pedersen ${ }^{6}$ are all for rock armoured slopes with crown walls whilst that of Owen ${ }^{7}$ is based on overtopping data from smooth slopes. Consequently, there is a need to quantify the overtopping performance of rock slopes of coastal structures without crown walls to enable improved designs of such structures in Sri Lanka.

Accordingly, the present study is primarily concerned with wave run-up and overtopping performance of a comparatively large-scale rubble-mound breakwater without a crown wall.

\section{METHODS AND MATERIALS}

The experiments were carried out in a large wave flume in the Fluids Laboratory of the University of Peradeniya. This flume consists of a plunger-type regular wave generator and a $40 \mathrm{~m}$ long, $2 \mathrm{~m}$ wide and $2.13 \mathrm{~m}$ deep smooth, concrete walled channel (Figure 1). A largescale model of a rock slope was laid on $18 \mathrm{~mm}$ thick plywood boards fixed to the rigid frame of steel girders 
installed at the far end of the channel. Two surface types were investigated: smooth and rough. It was decided to carry out both wave run-up and overtopping measurements over a smooth slope first to enable verification of the reliability of the present experimental set-up, prior to the study on the rubble-mound. The smooth surface was obtained by laying an Aluminum sheet over the wooden boards supported by the steel girders.

Two layers of stones were used for the armour layer of the straight rock slope without a crown wall. Each armor unit of angular shape was carefully selected, and the weight and a typical linear dimension were recorded: the weight of each stone ranged from $1.8 \mathrm{~kg}-2.0 \mathrm{~kg}$ and the nominal median diameter was $95 \mathrm{~mm}$. The weight of the filter layer ranged from $0.12 \mathrm{~kg}$ to $0.18 \mathrm{~kg}$, which is $1 / 10$ to $1 / 15$ of the armour unit weight. The nominal diameter of the stones used for the filter layer was $38 \mathrm{~mm}$. Two layers of filter material were placed on the impermeable plywood sheets fixed to the steel frame mentioned earlier, and therefore, the model can be described as a rough-impermeable rubble-mound with a notional permeability value $(P)$ of $0.1^{1,2}$.

The construction of the rubble mound was done very carefully to simulate the random placement of the units in the prototype. Hence, intentional close-packing and interlocking of armour units was avoided. The surface of the armour stones was painted white to reduce model roughness. The average slope of the rubble-mound was found to be $23.3^{0}$ to the horizontal. The structure was fronted with a toe berm, however, there was no sloping foreshore.

The wave parameters were recorded using an Armfield H40, resistant type, twin-wire probe. The use of a single probe meant that the wave parameters could not be obtained at the toe of the structure as the incident waves at a location so close to the structure get distorted by the waves reflected from the structure in no time. Therefore, the wave probe ought to be positioned some distance away from the structure to enable the recording of wave parameters before the waves reflected from the structure have had time to reach the probe. Accordingly, after several trial runs over a range of wave periods, the wave probe was placed at a location $10 \mathrm{~m}$ in front of the toe of the structure. The wave records at this location indicated that the reflected waves reach there only after about 12 - 15 incident waves have passed the probe. Accordingly, the wave parameters and the corresponding run-up or overtopping were always recorded for an incident wave that was not affected by the reflections from the structure. The wave parameters obtained in this way may be considered as 'deep water' conditions under the present experimental conditions.

A video camera was employed to obtain the wave run-up on the slope. The video clips obtained in this way were played on a Personal Computer (PC) at 25 frames per second to obtain run-up levels, averaged at $10 \mathrm{~cm}$ intervals over a $0.9 \mathrm{~m}$ width across the slope. Moreover, the run-up measurement for a given wave setting was repeated twice and the average was taken. About 115 tests were performed in this way to record the run-up levels over a range of values of the breaker parameter.

An RS Instruments load cell was employed for the measurement of wave overtopping quantities following the findings of Kortenhaus et al. ${ }^{8}$ regarding the accuracy of different methods of measuring wave overtopping discharges. A rectangular container in which overtopping water was to be collected was suspended from the load cell mounted on a rigid beam placed across the concrete walls of the wave flume. The data was sampled at a frequency of $40 \mathrm{~Hz}$ and the analogue signal from the load cell was fed to the computer via an analogue-to-digital converter for subsequent processing.

In most laboratory investigations of wave overtopping, the width of the overtopping tray is only a few centimeters. However, sensitivity tests conducted by Kortenhaus et al. ${ }^{8}$ with overtopping trays of different sizes indicate that wider trays tend to yield more accurate results, especially for low overtopping rates. Accordingly, in the present measurements, an overtopping tray spanning across the full-width of the test section, i.e., $0.9 \mathrm{~m}$, was employed so as to obtain a better average of the overtopping rate per metre width of the crest of the structure, especially at low discharges.

Relevant dimensionless groups: It will help in the interpretation of the experimental results if the relevant dimensionless groups are listed.

The wave run-up $(R)$ over a rough, impermeable slope under the present experimental conditions depends on $d_{s}$, the depth of water at the toe of the structure; $g$, the acceleration due to gravity; $H$, the wave height; $k$, the roughness height of the slope; $T$, the wave period; $\alpha$, the slope angle of the structure; and $\theta$, the slope angle of the foreshore.

Thus, the non-dimensional run-up $(R / H)$ may be expressed as a function of the following dimensionless groups: 


$$
\frac{R}{H}=\phi\left(\frac{g T^{2}}{H}, \frac{d_{s}}{H}, \frac{k}{H}, \tan \alpha, \tan \theta\right)
$$

Following Battjes ${ }^{9}$, we define a breaker parameter for wave action on slopes:

$\zeta=\frac{\tan \alpha}{\sqrt{s}}$, where, $s=\frac{2 \pi H}{g T^{2}}$.

As in many previous investigations of wave run-up on slopes ${ }^{1,10}$, the present study employs the breaker parameter $\zeta$ to represent the dual dependence of the nondimensional wave run-up on $g T^{2} / H$ and $\tan \alpha$.

On the other hand, the average overtopping discharge per unit length $(q)$ of a rough, impermeable slope under the present experimental conditions is a function of the following parameters:

$$
q=\psi\left[H, T, R_{c}, d_{s}, k, \beta, g, \text { structure geometry }\right]
$$

where, $R_{c}$ is the crest freeboard.

Two types of mathematical formulations have been widely employed in describing the overtopping rates:

and

$$
Q=a e^{-\left(b \Re_{c}\right)}
$$

$$
Q=a \Re_{c}^{-b}
$$

where, $Q$ is a dimensionless average discharge per metre, $\Re_{c}$ is a dimensionless freeboard, and $a$ and $b$ are coefficients specific to the geometry of the structure, as no general model is so far available to adequately describe the geometrical parameters of the structure profile including the crown walls.

Test conditions: The test ranges of the main parameters relevant to the present study of wave run-up and overtopping are summarized in Table 1 and Table 2, respectively. There are two sets of data in each Table: one for the smooth slope and the other for the rock slope. The nominal median diameter $\left(D_{n 50}\right)$ of the angular-shaped stones in the armour layer was $9.5 \mathrm{~cm}$ and that in the filter layer was $3.8 \mathrm{~cm}$; further details are given in section 2 . The wave impact on the slope was head-on, so $\beta=0 \mathrm{deg}$., and there was no sloping foreshore, i.e., $\theta=0 \mathrm{deg}$.

The values of some of these parameters corresponding to typical rubble-mound breakwaters used in Sri Lanka under storm wave conditions are as follows: mean wave height, $H=2-2.5 \mathrm{~m}$ (approximately corresponding to significant wave heights of $3-3.5 \mathrm{~m}$ ); mean wave period, $T=7-9 \mathrm{~s} ; d_{s}=3-5 \mathrm{~m} ; \alpha=26.6 \mathrm{deg}$.; and $D_{n 50}$ of armour layer $=1-1.5 \mathrm{~m}$. Table 3 compares the values of these parameters in non-dimensional form under typical field conditions with those tested in the present laboratory measurements. It may be noted that the field values of $D_{n 50} / H, \zeta$ and the ratio of armour layer/filter layer stone size $\left(D_{n 50}\right)$ fall within or closer to those investigated in the laboratory. However, the parameter $d_{s} / H$ in the field is $1.2-2.5$ indicating shallow water conditions whilst that tested in the laboratory ranges from 3 to 18 depicting largely deep water conditions. Consequently, if shallow water has any significant effect on the run-up and overtopping performance of coastal structures, such effects are not included in the present results. It must, however, be added that some of the major contributions to wave run-up and overtopping performance of coastal structures with crown walls, such as those of Van der Meer $^{1}$, Bradbury and Allsop ${ }^{3}$ and Owen ${ }^{7}$, have all used deep water conditions in their laboratory investigations.

\section{RESULTS AND DISCUSSION}

\section{Wave run-up measurements}

At the outset, a series of wave run-up measurements was made over a smooth slope to verify the reliability of the results from the present experimental set-up. Accordingly, Figure 2 compares the non-dimensional run-up measurements $(R / H)$ over the smooth slope with those of Ahrens ${ }^{10}$ and Van der Meer ${ }^{1}$ over a range of the breaker parameter $(\zeta)$. It must be added that both Ahrens and Van der Meer have used irregular waves whereas the present measurements are for regular waves. Nevertheless, it was possible to obtain the mean values of run-up required for the above comparison from the measurements of Ahrens ${ }^{10}$ and Van der Meer ${ }^{1}$ based on the assumption that the wave heights are Rayleigh distributed $^{3}$. It is noted that in Figure 2 the present measurements, which are available only for $1<\zeta<3$, show good agreement with those of Ahrens and Van der Meer.

Figure 3 shows the variation of relative run-up $(R / H)$ with breaker parameter $(\zeta)$ for the comparatively large rubble-mound slope investigated in the present study (nominal median diameter of armour layer stones, $D_{n 50}=$ $9.5 \mathrm{~cm})$. The measurements of Van der Meer ${ }^{1}$ over slopes covered with relatively smaller armour stones $\left(D_{n 50}=3.6\right.$ $\mathrm{cm})$ as well as his prediction formulae are also given in Figure 3 for comparison:

$$
\begin{aligned}
& \frac{R}{H}=a \xi \\
& \frac{R}{H}=b \xi^{c}
\end{aligned}
$$


Table 1: Test conditions of wave run-up measurements

\begin{tabular}{ccc}
\hline \multirow{2}{*}{ Parameter } & \multicolumn{2}{c}{ Study range } \\
\cline { 2 - 3 } & Smooth slope & Rock slope \\
\hline $\mathrm{H}$ & $7.3-28.1 \mathrm{~cm}$ & $6.0-24.7 \mathrm{~cm}$ \\
$\mathrm{~T}$ & $0.77-1.56 \mathrm{~s}$ & $0.83-1.43 \mathrm{~s}$ \\
$\mathrm{~d}_{\mathrm{s}}$ & $110 \mathrm{~cm}$ & $110 \mathrm{~cm}$ \\
$\zeta$ & $0.87-2.93$ & $1.05-3.05$ \\
$\alpha$ & $23.3 \mathrm{deg}$. & $23.3 \mathrm{deg}$. \\
\hline
\end{tabular}

Table 3: Comparison of test parameters in laboratory and field conditions

\begin{tabular}{lcc}
$\begin{array}{l}\text { Non-dimensional } \\
\text { parameter }\end{array}$ & $\begin{array}{c}\text { Present laboratory } \\
\text { measurements }\end{array}$ & $\begin{array}{c}\text { Field (under storm } \\
\text { wave conditions) }\end{array}$ \\
\hline $\mathrm{D}_{\mathrm{n}} 50 / \mathrm{H}$ & $0.3-1.6$ & $0.4-0.75$ \\
$\zeta$ & $0.9-3$ & $2.3-3.6$ \\
$\mathrm{~d}_{\mathrm{s}} / \mathrm{H}$ & $3-18$ & $1.2-2.5$ \\
Ratio of armour layer/ & 2.5 & $2-3$ \\
filter layer stone size & & \\
$($ Dn50) & & \\
\end{tabular}

where, the coefficients $a, b$ and $c$ are $0.72,0.88$ and 0.41 , respectively.

Clearly, the present results show good agreement with those of Van der Meer ${ }^{1}$ over the range of the relevant dimensionless parameters investigated. The good agreement between wave run-up measurements from regular (present study) and irregular waves (Ahrens ${ }^{10}$ and Van der Meer ${ }^{1}$ ) over both smooth (Figure 2) and rough slopes (Figure 3) appear to further justify the scaling of irregular wave data based on the assumption of Rayleigh distribution.

\section{Wave overtopping measurements}

Wave overtopping measurements were made first over the smooth slope and then over the large-scale rubblemound model described under Methods and Materials. The primary objective of the measurements over the smooth slope was again to verify the reliability of the present experimental set-up for wave overtopping tests, as smooth slope overtopping data are available from several past studies, for example, Van der Meer ${ }^{1}$. In the following, the results of wave overtopping measurements over the smooth and rock slopes are examine.

Figure 4 compares the present results of average overtopping rates over the smooth slope with the results reported in Owen ${ }^{7}$. As his measurements were made with irregular waves, the mean wave heights from the present study have been multiplied by a factor of 1.6 to obtain corresponding significant wave heights based on the
Table 2: Test conditions of wave overtopping measurements

\begin{tabular}{ccc}
\hline \multirow{2}{*}{ Parameter } & \multicolumn{2}{c}{ Study range } \\
\cline { 2 - 3 } & Smooth slope & Rock slope \\
$\mathrm{H}$ & $6.4-24.0 \mathrm{~cm}$ & $10.3-29.6 \mathrm{~cm}$ \\
$\mathrm{~T}$ & $1.06-1.64 \mathrm{~s}$ & $0.93-1.63 \mathrm{~s}$ \\
$\mathrm{~d}_{\mathrm{s}}$ & $80.0-100.0 \mathrm{~cm}$ & $92.0-104.5 \mathrm{~cm}$ \\
$\mathrm{R}_{\mathrm{c}}$ & $16.3-31.3 \mathrm{~cm}$ & $9.7-22.2 \mathrm{~cm}$ \\
$\alpha$ & $23.3 \mathrm{deg}$. & $23.3 \mathrm{deg}$. \\
\end{tabular}

assumption of Rayleigh distribution for wave heights in an irregular wave train.

The overtopping formula proposed by Owen ${ }^{7}$ is also shown in Figure 4:

$$
\frac{q}{g H_{s} T_{o m}}=a \exp \left[-b \frac{R_{c}}{H_{s}} \sqrt{\frac{s_{o m}}{2 \pi}} \frac{1}{\gamma_{r}}\right]
$$

where, $a=0.013$ and $b=22$ for the present experimental conditions. Despite the scatter of data points, present measurements on the whole show reasonably good agreement with Owen's formula.

As it is quite possible that the considerable scatter of data points in Figure 4 could be due to the Owen's scaling of overtopping rates $(q)$ and crest freeboard $\left(R_{c}\right)$, following Van der Meer ${ }^{1}$ we also plot the present results in Figure 5 with $q$ and $R_{c}$ made non-dimensional as given in equation (9).

$\frac{q}{\sqrt{g H_{s}^{3}}} \sqrt{\frac{s_{o p}}{\tan \alpha}}=f\left[\frac{R_{c}}{H_{s}} \frac{\sqrt{s_{o p}}}{\tan \alpha}\right]$

As observed in Figure 5, the present measurements of average overtopping rates over the smooth slope show good agreement with those of Owen ${ }^{7}$, and that the scatter of data points is less compared to the non-dimensional forms used in scaling of $q$ and $R_{c}$ in Figure 4 .

Figure 6 compares the present measurements of average overtopping quantities with Van der Meer $^{1}$ formula for $\zeta<2$. The middle line gives the formula proposed by Van der Meer ${ }^{1}$ together with $95 \%$ confidence bands on either side. The measurements reported in Van der Meer $^{1}$ over different types of wave and structure conditions are also plotted on the same figure. Clearly, the present measurements show good agreement with the measurements of Van der Meer and also mostly fall within the $95 \%$ confidence bands. The limited number of overtopping measurements available for $\zeta>2$ is shown in Figure 7. 
(a)

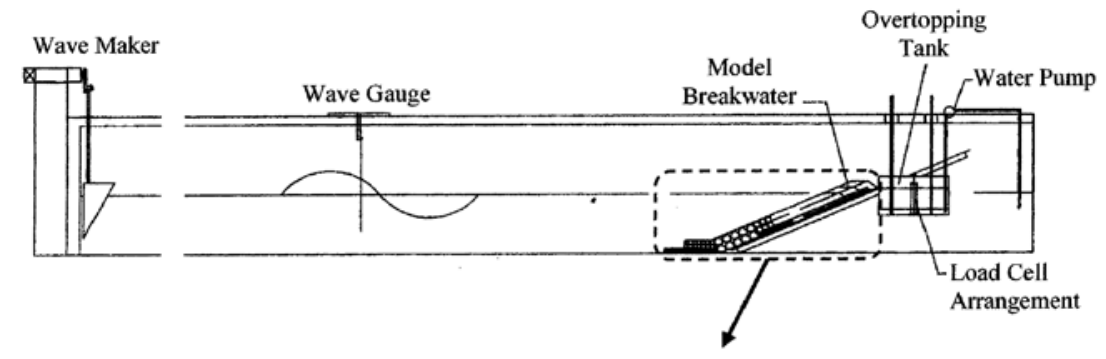

(b)

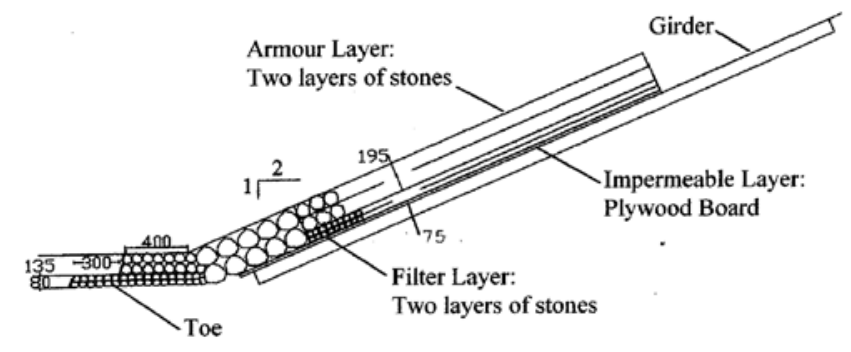

Figure 1: Experimental set-up: $a$ ) wave flume with measuring arrangement, and $b$ ) details of rock slope (all dimensions are in millimetres unless otherwise specified).

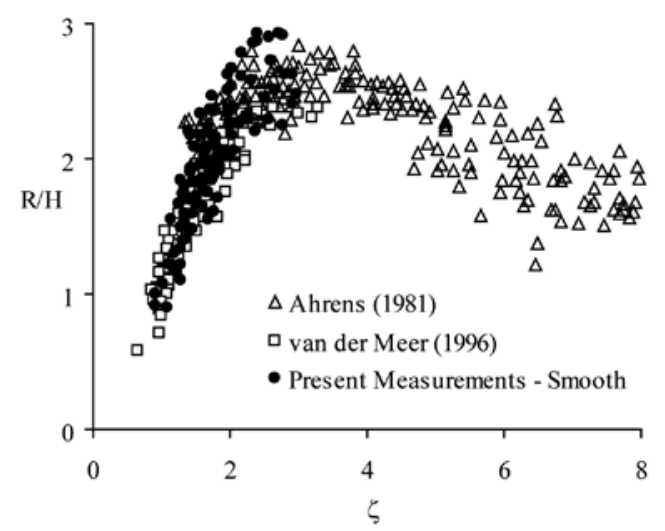

Figure 2: Variation of $R / H$ with $\zeta$ over a smooth slope. Measurements of Ahrens ${ }^{10}$ and Van der Meer ${ }^{1}$ are also shown for comparison.

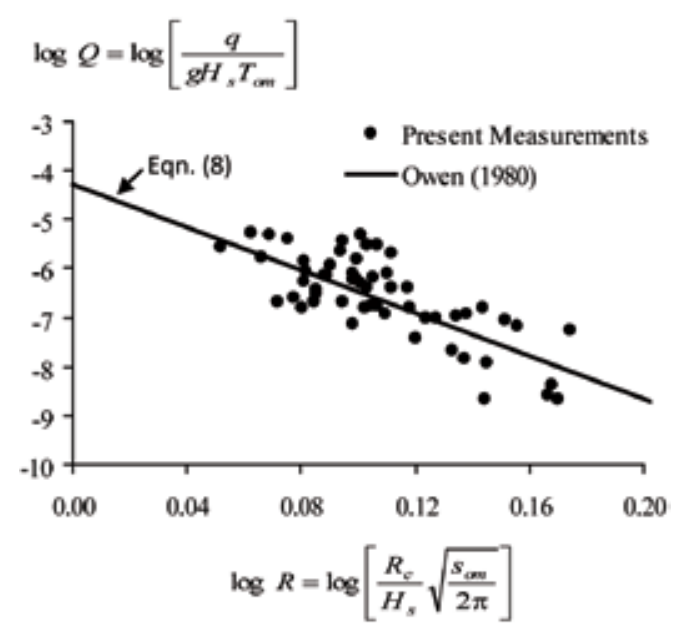

Figure 4: Comparison of present measurements of wave overtopping over the smooth slope with Owen's ${ }^{7}$ overtopping model.

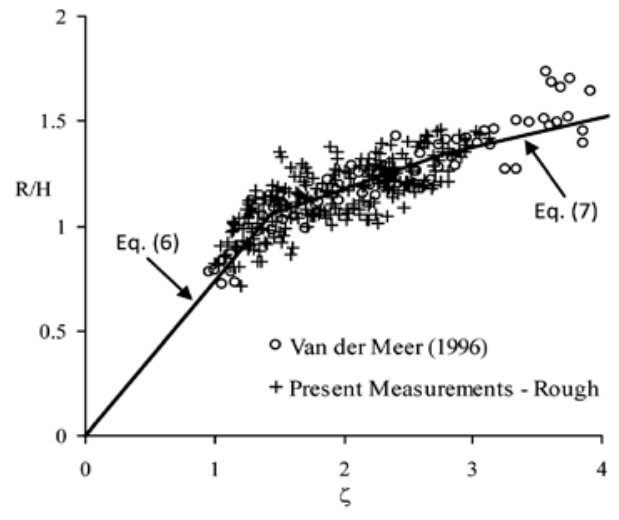

Figure 3: Variation of $R / H$ with $\zeta$ over the rock slope. Measurements of Van der Meer ${ }^{1}$ are also shown for comparison.

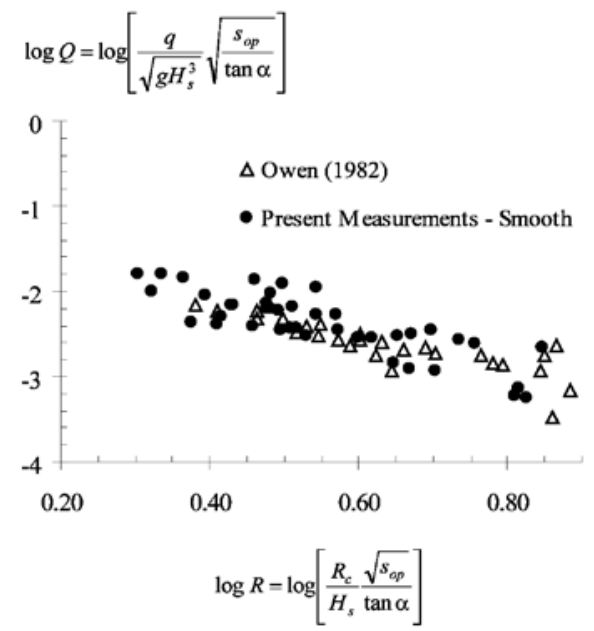

Figure 5: Comparison of present measurements of average overtopping rates with those of Owen ${ }^{7}$ following the scaling adopted by Van der Meer ${ }^{1}$. 


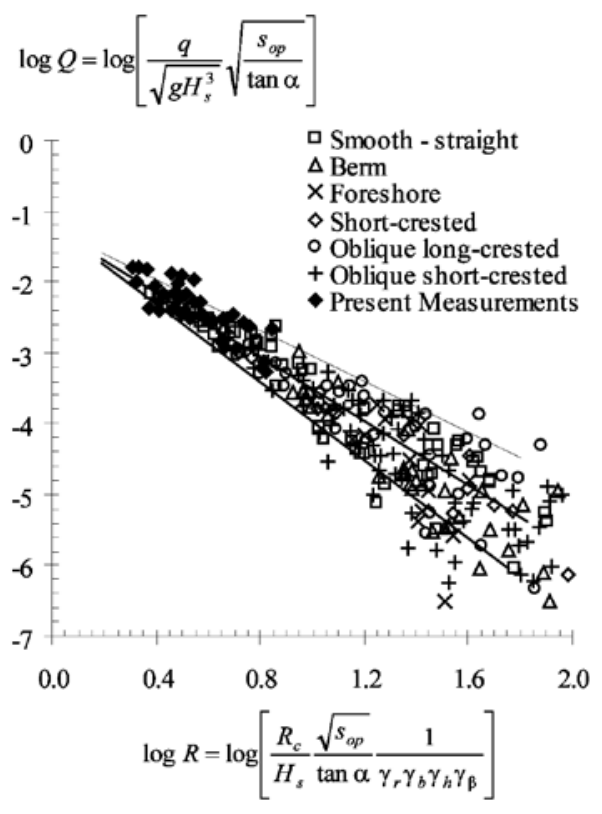

Figure 6: Comparison of present smooth slope measurements with Van der Meer ${ }^{1}: \zeta<2$.

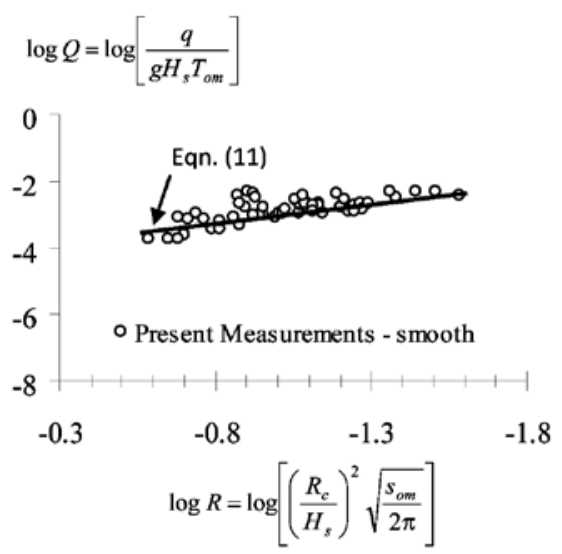

Figure 8: Smooth slope measurements scaled following Bradbury \& Allsop ${ }^{3}$.

It is also interesting to plot the present measurements using the overtopping model given by equation (10), which was employed by Bradbury and Allsop ${ }^{2,3}$ for their measurements over rock slopes with crown walls:

$$
\frac{q}{g H_{s} T_{o m}}=\phi\left[\left(\frac{R_{c}}{H_{s}}\right)^{2} \sqrt{\frac{s_{o m}}{2 \pi}}\right]
$$

Figure 8 indicates that the present results over the smooth slope appear to scale well with the functional relation in (10), and the equation of the line passing through the data points is:

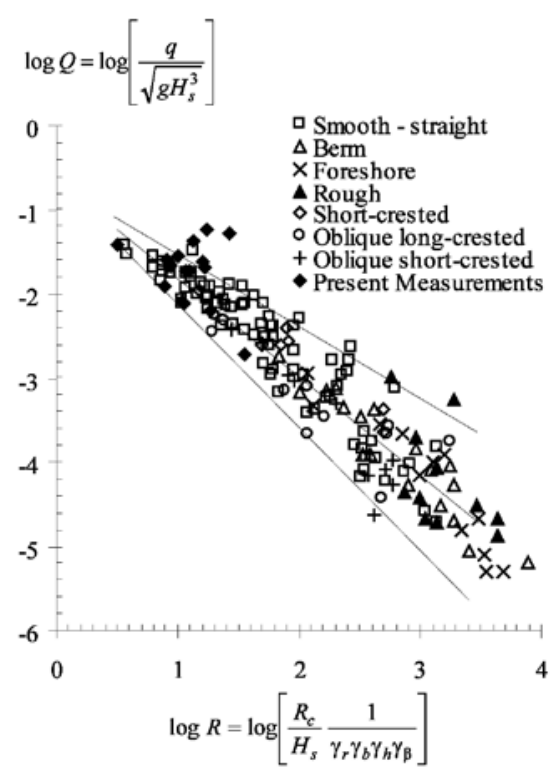

Figure 7: Comparison of present smooth slope measurements with Van der Meer' ${ }^{1}: \zeta>2$.

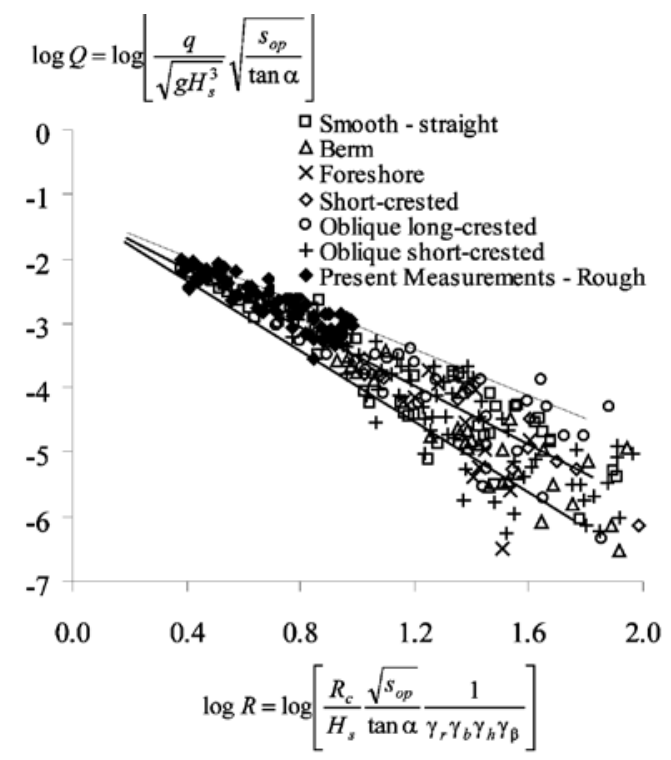

Figure 9: Comparison of present rock slope measurements with Van der Meer' ${ }^{1} \zeta<2$.

$\frac{q}{g H_{s} T_{o m}}=0.00005\left[\left(\frac{R_{c}}{H_{s}}\right)^{2} \sqrt{\frac{s_{o m}}{2 \pi}}\right]^{-0.57}$

The overtopping performance of the straight, rubblemound structure without a crown wall investigated in the present study is not considered. Figure 9 compares the average wave overtopping rates over the rubblemound breakwater for $\zeta<2$ from the present study is consider with the measurements of Van der Meer ${ }^{1}$ and 


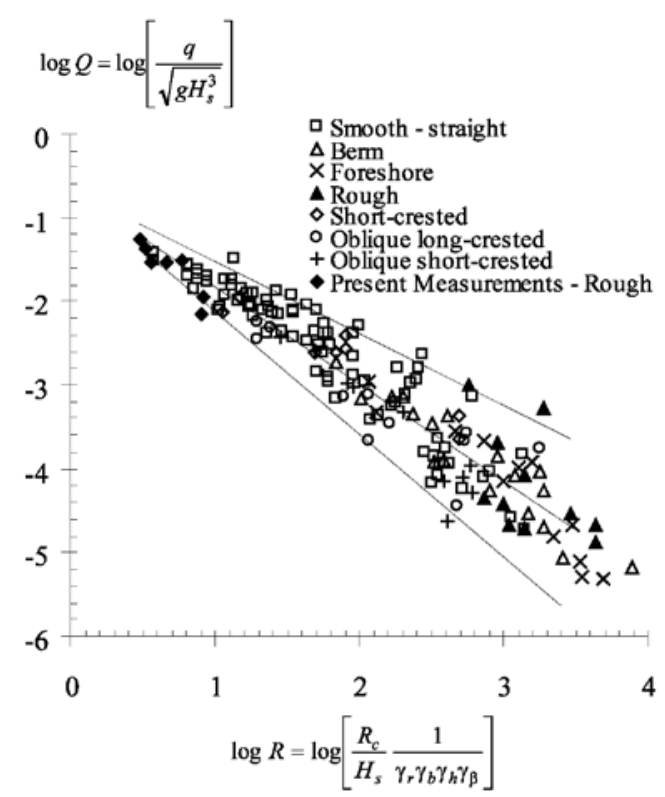

Figure 10: Comparison of present rock slope measurements with Van der Meer ${ }^{1}: \zeta>2$.

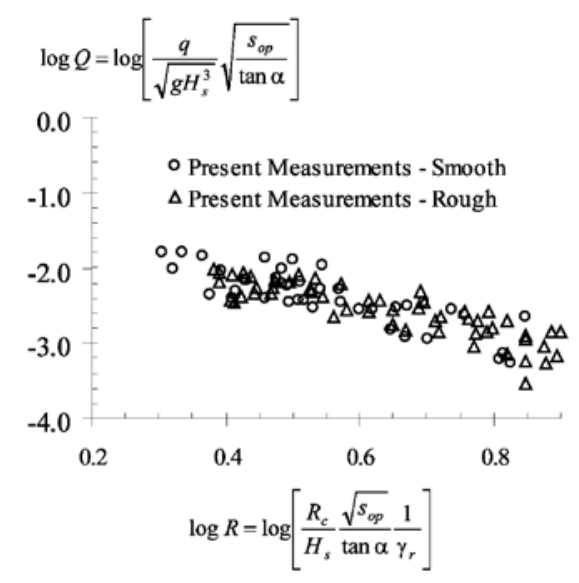

Figure 12: Comparison of measured average overtopping rates over the rock and smooth slopes employed in the present study.

the formula proposed by the same author. A roughness reduction factor $\left(\gamma_{r}\right)$ of 0.55 has been used for the present measurements. Clearly, we see a good agreement between the present measurements and those of Van der Meer with present data points mostly falling within the $95 \%$ confidence bands. Similarly, the limited number of measurements available for $\zeta>2$ is compared with the measurements of Van der Meer ${ }^{1}$ in Figure 10.

It may now plot the present rock slope measurements in Figure 11 using the non-dimensional crest freeboard and overtopping parameters employed by Bradbury \& Allsop ${ }^{3}$ :

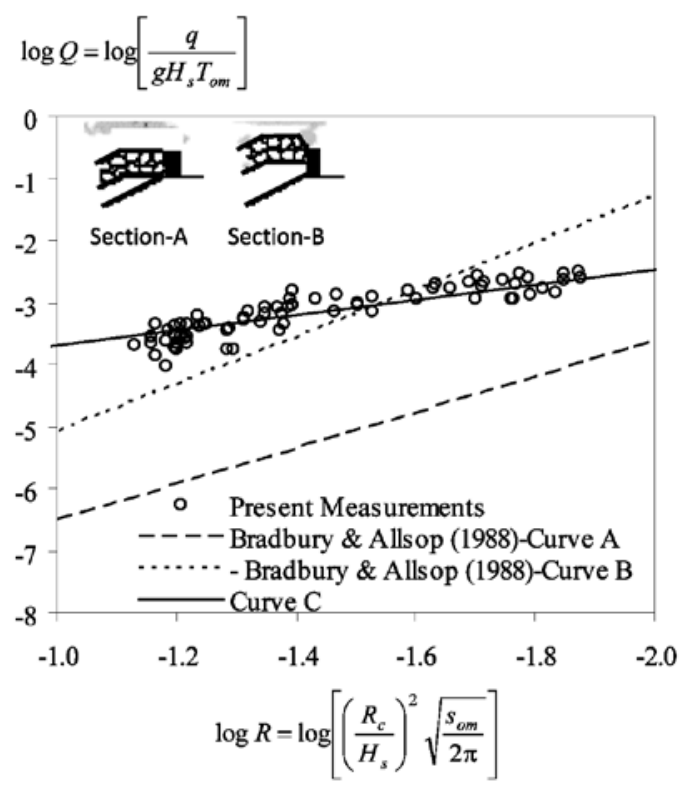

Figure 11: Present rock slope measurements scaled using the overtopping model adopted by Bradbury \& Allsop ${ }^{3}$.

$\frac{q}{g H_{s} T_{o m}}=a\left[\left(\frac{R_{c}}{H_{s}}\right)^{2} \sqrt{\frac{s_{o m}}{2 \pi}}\right]^{-b}$

where, $a$ and $b$ are coefficients that depend primarily on the structure geometry. Figure 11 clearly indicates that the present measurement scale ${ }^{5}$ well with the functional relation given in equation 12 .

It must be added that Bradbury \& Allsop ${ }^{3}$ employed several configurations of rock armoured slopes with a crown wall: of the five geometries tested, only the two sections shown as an inset in Figure 11 may be considered for comparison with the present data set. Equation 12 is also plotted in Figure 11 with $a$ and $b$ values applicable to these two sections; curve- $A\left(a=3.7 \times 10^{-10}, b=2.9\right)$ and curve- $B\left(a=1.3 \times 10^{-9}, b=3.8\right)$ corresponding to sections $-A$ and $-B$, respectively.

The overtopped water has to travel over the width of three stones plus the width of the crown wall in the case of section- $A$, whereas only over the width of three stones in the case of section- $B$. It is noted that curve- $B$ falls closer to the present measurements, albeit with a different gradient, than curve- $A$. This, however, is not entirely surprising because the overtopping performance of section- $B$ may be considered closer to the section employed in the present study with three stones over the crest and without a crown wall. On the other hand, 
equation 13 , i.e., curve- $C$, with $a=1.3 \times 10^{-5}$ and $b=1.22$ agrees better with the present overtopping measurements for the rock slope without a crown wall.

Finally, it is also interesting to compare the present overtopping measurements for the rock slope with those for the smooth slope (Figure 12). The non-dimensional discharge and free-board parameters suggested by Van der Meer ${ }^{1}$ with a roughness reduction $\left(\gamma_{\mathrm{r}}\right)$ value of 0.55 for the rock slope was employed in the present investigation. Clearly, both sets of measurements scale well and a $\gamma_{r}$ value of 0.55 appears suitable for the geometry of the rock slope employed in the present study.

\section{CONCLUSION}

The following conclusions are drawn for the range of conditions covered in the present experimental investigation of the wave run-up and overtopping performance of a smooth as well as a rock slope. The present non-dimensional regular wave run-up $(R / H)$ over both the smooth and rock slopes show good agreement with the measurements reported in Ahrens ${ }^{10}$ and Van der Meer ${ }^{1}$ with irregular waves. This comparison also appears to confirm that the run-up measurements for regular waves, if appropriately scaled based on Rayleigh probability distribution, can be used to estimate run-up heights with a desired probability of exceedence, for example, $2 \%$ or $33 \%$ (significant) exceedence.

The average overtopping rates measured over the smooth slope show good agreement with the previous measurements of Owen ${ }^{7}$ as well as with the overtopping formulae proposed by Owen ${ }^{7}$ and Van der Meer ${ }^{1}$. The present measurements also appear to scale well with the form of non-dimensional discharge and freeboard adopted by Bradbury and Allsop ${ }^{3}$ for their measurements over rock slopes fronted by a berm and a crown wall.

Moreover, the average overtopping discharges for the comparatively large-scale rock slope tested in the present study show good agreement with the previous measurements reported in Van der Meer ${ }^{1}$ when scaled with a roughness reduction factor of 0.55 . The overtopping measurements for the rock slope without a crown wall have also been compared with the overtopping model employed by Bradbury and Allsop ${ }^{3}$ for their measurements over rock slopes with crown walls.

\section{Acknowledgement}

Messers. V. Vinovan and D.M. R. Sampath, respectively are thanked, for their assistance in carrying out the wave overtopping and run-up experiments described in the present paper. The reviewers are also thanked for their useful comments on the manuscript. This investigation received financial support from the NSF under Grant No. $\mathrm{RG} / 2004 / \mathrm{E} / 03$.

\section{References}

1. Van der Meer J.W. (1996). Conceptual design of rubble mound breakwaters, In: Ed. (Philip L.-F. Liu) Advances in Coastal and Ocean Engineering, Vol. 1, World Scientific, Singapore, pp. 221-315.

2. Coastal Engineering Research Centre, U.S. Army (2002). Coastal Engineering Manual, The U.S. Government Printing Office, Washington D.C.

3. Bradbury A.P. \& Allsop N.W. (1988). Hydraulic effects of breakwater crown walls. Proceedings of the Breakwaters '88 Conference, Institution of Civil Engineers, Thomas Telford Publishing, London, pp. 385-396.

4. Aminti P. \& Franco L. (1988). Wave overtopping on rubble mound breakwaters, Proceedings of the $21^{\text {st }}$ International Coastal Engineering Conference, American Society of Civil Engineers, Vol. 1, pp. 770-781.

5. Pedersen J. \& Burcharth H.F. (1992). Wave forces on crown walls. Proceedings of the $23^{\text {rd }}$ International Coastal Engineering Conference, American Society of Civil Engineers, Vol. 2, pp. 1489-1502.

6. Pedersen J. (1996). Experimental study of wave forces and wave overtopping on breakwater crown walls. Series Paper 12, Hydraulics \& Coastal Engineering Laboratory, Department of Civil Engineering, Aalborg University, Denmark.

7. Owen M.W. (1980). Design of seawalls allowing for wave overtopping, Report No. 924, Hydraulics Research Station, Wallingford, UK.

8. Kortenhaus A., Oumeraci H., Geeraerts J. \& de Rouck J. (2004). Laboratory effects and further uncertainties associated with wave overtopping measurements. Proceedings of the International Conference on Coastal Engineering, Lisbon, pp. 4456 4468.

9. Battjes J.A. (1974). Computation of set-up, longshore currents, run-up and overtopping due to wind-generated waves, Report 74-2, Committee on Hydraulics, Department of Civil Engineering, Delft University of Technology, Delft, the Netherlands.

10. Ahrens J.P. (1981). Irregular wave run-up on smooth slopes, Tech. Aid No. 81-17, Coastal Engineering Research Centre, Waterways Experiment Station, Vicksburg, Mississippi. 